\title{
Chapter 2 \\ Climate Policy in the Commercial Sector: A Survey of Commercial Buildings in Japan
}

\author{
Hiroki Onuma and Toshi H. Arimura
}

\begin{abstract}
In Japan, the government has set a target for a reduction in greenhouse gas (GHG) emissions by $26 \%$ from 2013 levels by 2030. The commercial sector has the highest reduction target-39.8\% - among all Japanese sectors. This chapter first presents the current GHG situation in Japan and Japanese climate policy in the commercial sector. Second, we introduce a nationwide survey that we conducted on the implementation of energy efficiency measures (EEMs) in office buildings with large-scale emissions in Japan. The survey results show that energy-saving technology adoption is more advanced in Tokyo than in other prefectures and that there is more space for the adoption of energy-efficient technologies nationwide. To accelerate EEM adoption to achieve the 2030 target, regulatory agencies must improve the way they promote energy audits and subsidies and provide information on energy savings.
\end{abstract}

Keywords Energy efficiency measures $\cdot$ Office building $\cdot$ Emissions trading scheme $\cdot$ Energy conservation act $\cdot$ Energy audit

\section{Commercial Sector's Position in Japan's NDC}

To accomplish the Paris Agreement goals of holding the increase in the global average temperature to well below $2{ }^{\circ} \mathrm{C}$ above preindustrial levels and pursuing efforts to limit the temperature increase to $1.5^{\circ} \mathrm{C}$ above preindustrial levels, countries all over the world have set their targets for post-2020 climate actions. In Japan, the government has set a target for a reduction in greenhouse gas (GHG) emissions by $26 \%$ from 2013 levels by 2030 (see Table 1).

\footnotetext{
H. Onuma ( $\square)$

Research Institute of Economy, Trade and Industry (RIETI), 1125 (11th floor), Annex, Ministry of Economy, Trade and Industry (METI), 1-3-1 Kasumigaseki, Chiyoda-ku, Tokyo 100-8901, Japan e-mail: h.onuma.ac@gmail.com
}

H. Onuma · T. H. Arimura

Waseda University, Tokyo, Japan

T. H. Arimura and S. Matsumoto (eds.), Carbon Pricing in Japan, 
Table 1 Japan's GHG emissions target (by 2030)

\begin{tabular}{c|l|l|l|l}
\hline Unit: million t-CO & $\begin{array}{l}\text { Estimated } \\
\text { emissions in } \\
\text { FY 2030 }\end{array}$ & $\begin{array}{l}\text { Actual } \\
\text { emissions in } \\
\text { FY 2013 }\end{array}$ & $\begin{array}{l}\text { Compared to } \\
\text { FY 2013 }(\%)\end{array}$ & $\begin{array}{l}\text { Percentage of } \\
\text { total }(\%)\end{array}$ \\
\hline Energy-originated $\mathrm{CO}_{2}$ & 927 & 1235 & -25.0 & -21.9 \\
\hline Industry sector & 401 & 429 & -6.5 & -2.0 \\
\hline $\begin{array}{c}\text { Commercial and other } \\
\text { sectors }\end{array}$ & 168 & 279 & -39.8 & -7.9 \\
\hline Residential sector & 122 & 201 & -39.3 & -5.6 \\
\hline Transport sector & 163 & 226 & -27.6 & -4.5 \\
\hline Energy conversion sector & 73 & 101 & -27.7 & -2.0 \\
\hline Other GHGs & 152.4 & 173 & -11.9 & -1.5 \\
\hline $\begin{array}{c}\text { Non-energy-originated } \\
\text { CO }\end{array}$ & 70.8 & 75.9 & -6.7 & -0.4 \\
\hline Methane $\left(\mathrm{CCH}_{4}\right)$ & 31.6 & 36.0 & -12.3 & -0.3 \\
\hline Nitrous oxide $\left(\mathrm{N}_{2} \mathrm{O}\right)$ & 21.1 & 22.5 & -6.1 & -0.1 \\
\hline $\begin{array}{c}\text { Fluorinated gases }(\mathrm{HFCs}, \\
\left.\text { PFCs, } \mathrm{SF}_{6}, \mathrm{NF}_{3}\right)\end{array}$ & 28.9 & 38.6 & -25.1 & -0.7 \\
\hline $\begin{array}{l}\text { Carbon sink }\left(\mathrm{LULUCF}^{\mathrm{a}}\right. \\
\text { sector) }\end{array}$ & -37.0 & & & -2.6 \\
\hline Total & 1042.4 & 1408.0 & -26.0 & -26.0 \\
\hline
\end{tabular}

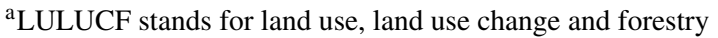

Within this national emission reduction target, the government has set different emission target levels for each sector. The reduction target for the industrial sector is $6.9 \%$, and the target for the transportation sector is $26.9 \%$. The commercial sector has the highest reduction target-39.8\% — among all Japanese sectors.

Japan's GHG emissions had not declined below 1990 levels since statistics started being collected in 1990 (excluding 2009 due to the bankruptcy of Lehman Brothers) before finally doing so in 2018 (MOE 2019). In 2018, the emission level was 1244 million tons of carbon dioxide $\left(\mathrm{CO}_{2}\right)$ equivalent, representing a decrease of $3.6 \%$ (47 million tons) from the previous year, after decreasing for five consecutive years. Although the main contributor to emission reductions relative to 1990 levels is the industrial sector, emissions over the past five years in other sectors, such as the commercial, residential, and transportation sectors, have also declined (see Fig. 1). However, the commercial and residential sectors have not reduced their emissions enough compared to 1990 levels. The reasons for the higher emissions in these two sectors are the increase in fossil fuel power generation after the Great East Japan Earthquake on March 11, 2011; the expansion of building floor areas; and the increase in the number of households, which has led to a growth in energy use.

To achieve Japan's emissions target under the Paris Agreement, it is crucial to accelerate the adoption of energy efficiency measures (EEMs) for the reduction of GHGs. In 2010 and 2011, respectively, Tokyo and its neighboring prefecture Saitama 


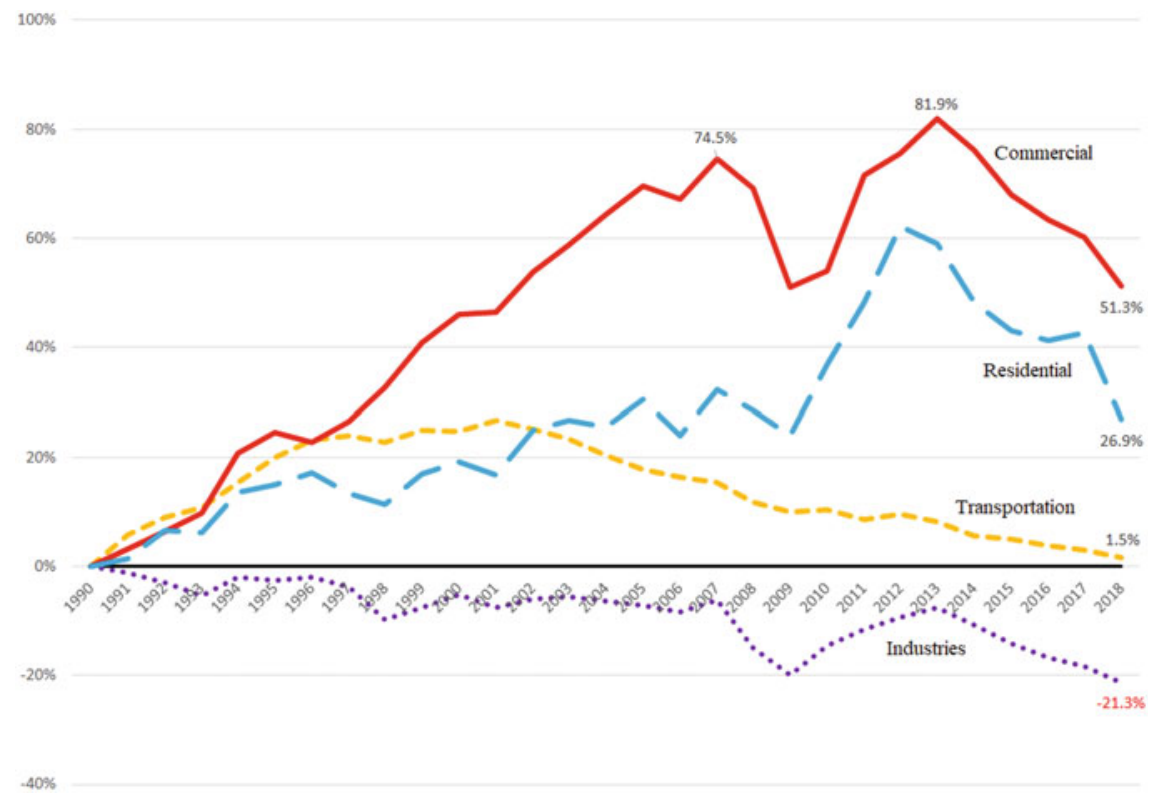

Fig. $1 \mathrm{CO}_{2}$ emissions change by sector since 1990

introduced an emissions trading scheme (ETS), which is a policy tool involving effective mitigation measures for the commercial sector. ${ }^{1}$ These schemes seem to have led to a reduction in GHGs in both prefectures (Arimura and Abe 2020), although it is unclear how the reduction was achieved.

Based on this background, we conducted a nationwide survey of EEM implementation in 906 commercial buildings with large-scale emissions to clarify how GHGs were reduced. This chapter explains the outline of the survey and compares the EEMs and technology adoption status of commercial buildings in Tokyo, where an ETS is implemented, with those of commercial buildings in areas where there is no ETS. Based on the survey results, we discuss the possibility of EEM diffusion among commercial buildings by introducing ETSs.

The remainder of this chapter is organized as follows. The next section describes Japan's current energy and climate change policies in the commercial sector. Section 3 presents how office buildings can conserve the energy consumption and GHG emissions. Section 4 provides an overview of our survey and the survey results. Section 5 concludes the chapter.

\footnotetext{
${ }^{1}$ See Chap. 6 for the Tokyo ETS and Chap. 7 for the Saitama ETS in this book.
} 


\section{Japan's Energy and Climate Change Policies in the Commercial Sector}

This section provides an overview of Japan's energy and climate change policies in the commercial sector (based on the Ministry of Economy, Trade and Industry (METI) 2018; Arimura and Iwata 2015).

Japan's energy consumption efficiency (final energy consumption amount/real GDP) has improved by approximately $40 \%$ since the oil crises in the 1970 s due to the combined efforts of the public and private sectors.

After the first oil crisis in 1973, an act on the rational use of energy (known as the "Energy Conservation Act"; ECA) was enacted in 1979 (enforced in October 1979) with the goal of efficient energy use in the context of energy security. The act obligates plants and offices with a large amount of energy consumption (crude oil equivalent of $1500 \mathrm{kl} /$ year) to report the state of their EEMs and improvements in energy consumption efficiency every year and to develop medium- and long-term plans for energy efficiency. ${ }^{2}$ It also establishes a target of a $1 \%$ reduction in energy intensity annually. In addition, regulated facilities must appoint qualified energy managers to promote energy management at plants and offices.

The initial objective of the ECA was to reduce energy consumption rather than GHG emissions, but reducing energy consumption results in a decline in fossil fuel consumption. Therefore, the goal of the ECA was aligned with reducing GHG emissions even before climate change was recognized as a major policy issue.

In the first commitment period of the Kyoto Protocol, energy conservation in Japan had two purposes. The first purpose was energy conservation to address energy security issues motivated by the oil shocks in the 1970s. Now, the purpose of energy conservation is to reduce GHG emissions.

Naturally, when the first commitment period began, the act was viewed as a measure to combat climate change and to contribute to achieving the Kyoto Protocol target plan published by the Cabinet Public Relations Office (2005). This plan emphasized that the objective of the ECA included reducing GHG emissions. The plan projected a 3 million ton reduction in emissions in the commercial and residential sectors.

In 2016, METI introduced a new system, the evaluation system for business operator classification. In this system, METI refers to facilities or a group of facilities as "business operators", which is a unit of regulation. Business operators that submit periodic reports are categorized into four classes. If the performance of a business operator is superior, the operator is ranked as Class $\mathrm{S}^{3}$ and is publicized as "superior in energy conservation efforts" on METI's homepage. If the performance is average, the operator is categorized as Class A and recognized as a "general business operator". If the energy conservation efforts are not progressing as expected, the operator is ranked as Class B. Class B business operators receive a written notice that their

\footnotetext{
${ }^{2}$ In 2002, the ECA was revised to require the commercial sector to submit regular reports.

${ }^{3}$ In 2016, 56.7\% of firms were categorized as Class S. Class A composed 29.2\%, and Class B accounted for $14.0 \%$ of the total. No firms were categorized as Class C (METI website).
} 
energy conservation efforts are not progressing, and they may face various levels of intervention, such as on-site inspections or collection of reports by the regulatory organization. A business operator can be classified as Class $\mathrm{C}$ after inspection if its efforts toward energy conservation are poor. If an operator is ranked as Class C, it must receive administrative guidance (shido). If the performance is still poor even after receiving guidance, the operator is required to make a plan for energy conservation. If it does not follow the directions, the business operator's name is published as a penalty, and it faces an order from the regulatory agency. In 2016, no business operator was classified as Class $\mathrm{C}$.

Among policy measures under the act, the Top Runner Program, which includes fuel efficiency standards, is well known. The Top Runner Program was introduced by an amendment to the ECA in 1998. This measure designates products with distinctions such as appliances and cars, indicates numerical criteria based on the best products in energy efficiency at that time, and requires manufacturers and importers to make their products comply with the threshold by a target year. Until now, energysaving efforts in the commercial and residential sectors have progressed under the Top Runner Program. For example, as of FY2016, compared to FY2001 levels, the efficiency of air conditioners improved by $28 \%$, that of TV sets improved by $71 \%$, and that of household electric refrigerators improved by $252 \%$.

In the commercial and residential sectors, energy efficiency improvements in buildings and houses are expected to be the most effective way to conserve energy. Using high-performance construction materials for openings and walls in which heat dissipates is especially effective. However, these materials were not originally included in the items of the Top Runner Program, which sets the standards for the energy consumption efficiency of machines and instruments in Japan.

To promote EEMs in the building and housing sector as above, the government of Japan added products that contribute to the improvement of the energy efficiency of buildings, houses, and other products in the scope of the Top Runner Program. For that purpose, the ECA was revised in 2013, and as a result, construction materials were added to the scope of the program.

The Top Runner Program for building insulation materials now includes building materials that contribute to the prevention of heat loss in buildings and/or houses. More specifically, "insulation used in envelope" and "glass and frames used in windows" are now included in the program. The program includes the following three types of building materials: extruded polystyrene foam, glass wool, and rock wool. The following three categories of materials are excluded from the scope of building materials covered by the new Top Runner Program: (1) building materials used for special applications, (2) building materials for which no technical measurement or assessment methods have been established, and (3) building materials whose share of use in the market is exceedingly small. The insulation standards for insulation materials, windows, and sashes are specified.

Setting energy efficiency standards can be expected to reduce energy consumption through technological innovation. Using data from seven European countries, Noailly (2012) investigates the impact of environmental policy instruments such as regulatory energy standards in building codes on technological innovations aiming 
to improve energy efficiency in buildings. The study finds that strengthening the minimum insulation standards for walls by $10 \%$ would increase the likelihood of additional patent filings for specific technologies related to energy efficiency in buildings by approximately $3 \%$.

In addition, energy-consuming equipment such as commercial electric refrigerators and freezers, multifunction devices, printers, electric water heaters (heat pump water heaters) and light-emitting diode (LED) lamps were newly added to the items of the Top Runner Program in 2013. The Japanese government has positioned LED lighting as an important measure against global warming and plans to replace all conventional (incandescent and fluorescent) lamps and lighting in homes, offices, and factories with LED lamps and lighting on a flow basis by 2020 and on a stock basis by 2030. To that end, in April 2019, the energy consumption efficiency target, which had been set separately for conventional lamps and lighting and LED lamps and lighting, was unified into a common target.

Furthermore, the government of Japan has promoted the renovation and rebuilding of existing buildings and houses with high energy efficiency performance. In addition, the government has encouraged the adoption of energy-efficient technologies such as high thermal insulation in new buildings and houses. As of the end of FY2017, the government had supported approximately 28,000 projects as measures to achieve net zero energy ${ }^{4}$ by introducing the abovementioned energy-efficient technologies in public and commercial buildings, houses and hospitals across the nation.

The Japanese government also aims to achieve net zero energy buildings (ZEBs) on average in newly constructed nonresidential buildings by 2020 and newly constructed public buildings by 2030 nationwide. For this goal, the government utilizes the Top Runner Program for building materials and coordinates with measures pertaining to the promotion of the introduction of renewable energy, which is essential for ZEBs. Moreover, in promoting ZEBs, it is important to demonstrate how the prices of high-energy performance building materials can be reduced.

With the aim of achieving ZEBs, the government of Japan has also decided to phase in an obligation for newly constructed buildings and houses to meet the energy efficiency standards by 2020, with due consideration given to the need for and degree of regulation. The obligation to meet the standards has started to be phased in for large-scale nonresidential buildings based on the Act for the Improvement of Energy Consumption Performance of Buildings (Building Energy Efficiency Act) established in 2015. The act was revised in 2019 and will be expanded to small and medium-sized buildings starting in April 2021.

The realization of a low-carbon society will be advanced by implementing various policy measures, such as the Top Runner Program based on the ECA and the Building Energy Efficiency Act. These policy measures have contributed to the progress of energy-efficient technological innovation. However, the extent to which new energyefficient technologies have been adopted in society remains an open question.

\footnotetext{
4"Net zero" means zero by subtracting energy production from energy consumption. This can be achieved if energy demands such as electricity and heat can be met with energy that does not emit GHGs. For more details, please see Chap. 3.
} 
As a policy measure aiming to spread technology use in society, carbon pricing (CP), such as an ETS or carbon tax, has come under the global spotlight after the Paris Agreement entered into force. In Japan, the government has set a long-term target for the reduction of GHG emissions, and the importance of CP has been reaffirmed as an effective mitigation tool. At the national level, however, Japan has failed to adopt $\mathrm{CP}$ at a level that can substantially reduce GHGs: only two prefectures, Tokyo and Saitama, have introduced an ETS. Additionally, a carbon tax was set in 2012, but the price level is insufficient compared with that of other countries that have set a carbon tax. The Tokyo ETS is the first ETS in the world adopted for the commercial sector. For more details about the Tokyo ETS, please see Chap. 6 and Arimura and Abe (2020). One year after the introduction of the Tokyo ETS, Saitama launched the Target Setting Emissions Trading System. This system is similar in many respects to the Tokyo ETS but differs from the Tokyo ETS in that there are no penalties if the target facility does not meet its emissions targets. For more details about the Saitama ETS, please see Chap. 7 and Hamamoto (2020).

In addition to the lack of an appropriate $\mathrm{CP}$ level, there are other barriers to the adoption of energy-efficient technologies. For example, facilities do not adopt such technologies even though the savings from the installation of the technologies exceed the costs. This is known as the energy efficiency gap (Gillingham and Palmer 2014). There are several reasons for this gap. First, facility managers may not have accurate information on energy-efficient technologies. Second, facilities may face liquidity constraints and hence be unable to invest in expensive technologies even though the net benefit of the investment is positive. Finally, it may be difficult for stakeholders to reach a consensus on investment due to the complexity of organizations (DeCanio 1998).

The Japanese government is implementing policy measures to overcome these barriers in energy. For example, the Ministry of the Environment Japan implements energy audits 5 called the "Assessment of $\mathrm{CO}_{2}$ Emission Reduction Potential $\left(\mathrm{CO}_{2}\right.$ sakugen potensharu shindan)", 6 and METI implements the "Energy-saving Diagnostic (sho-ene shindan)". 7 These two types of diagnostics by the MOE and METI often come with subsidies for energy-efficient technologies or appliances, often in compliance with the Top Runner Program (MOE website). They also provide reduced-rate loans for investments in energy-efficient technologies (DBJ website). Furthermore, they often implement demonstrations of new innovative technologies such as ZEBs. Through these various programs, the national government and local

\footnotetext{
${ }^{5}$ According to Babatunde et al. (2019), an energy audit is effective as an energy management tool that helps in the identification and implementation of strategies for achieving energy efficiency and conservation. It can also help extend the equipment/system lifespan, which, in the long run, translates into savings in terms of capital and reductions in emissions.

${ }^{6}$ In 2014 (2015), $\mathrm{CO}_{2}$ emission reduction potential was assessed at 362 (138) facilities. Among them, 238 (26) facilities belonged to service centers including commercial buildings (MRI 2016).

${ }^{7}$ For example, with funding from METI and the MOE, Energy Conservation Center Japan has conducted more than 10,000 audits (https://www.asiaeec-col.eccj.or.jp/energy-audit-program/, accessed on March 15, 2020).
} 
governments in Japan are engaged in the promotion of low carbon or decarbonization in commercial buildings.

The next section introduces a survey that tried to clarify the effect of $\mathrm{CP}$, especially in the Tokyo ETS, on technology adoption in office buildings. The results of the survey are presented.

\section{How Can Energy Efficiency Be Promoted in Office Buildings?}

How can we promote energy conservation in office buildings? There are two channels to that end. First, buildings can adopt energy-efficient technologies. Olsthoorn et al. (2017) present some examples of energy-efficient technologies related to the energy use of buildings in the commerce and service sectors. These examples include replacing lighting with more efficient alternatives, such as LED bulbs; applying insulating materials to the outer faces of a building, such as the roof or the outer walls; installing better insulating windows; substituting older, less efficient heating systems with more efficient ones, such as new condensing boilers; and adopting add-on digital technology for the optimization of heating system operations, which involves energetic optimization of the heating system, such as through hydraulic adjustments, nighttime turndown, dynamic control, or thermostat lowering. We refer to these methods of energy efficiency improvement as technological measures (TMs).

Second, improvement in energy efficiency can be achieved through nontechnological measures (NTMs). For example, buildings can reduce their energy consumption by appropriately setting the temperatures of air conditioners. The MOE recommends air conditioner temperatures of $28{ }^{\circ} \mathrm{C}$ in summer and $20{ }^{\circ} \mathrm{C}$ in winter. Other examples are turning off lights or PCs when unused, operating existing equipment in a highly efficient way and encouraging equipment users to perform energy-saving actions.

\section{Survey of Office Buildings in Japan}

\subsection{Overview of the Survey}

This section first explains the survey sampling period and method. Then, it introduces the main questions about EEMs and basic building information. 


\subsubsection{Survey Period and Target Buildings}

We conducted a nationwide survey in Japan of buildings whose main usage was for offices. We sent questionnaires and collected responses from October to December 2018. The surveyed office buildings were so-called large-scale GHG emission buildings, which consumed $1500 \mathrm{kl}$ or more of crude oil equivalent of energy (electricity, gas, fuel, etc.) per year in FY2015. As of 2006, these buildings are obligated to report their GHG emissions annually under the Greenhouse Gas Emissions Accounting, Reporting, and Disclosure System, in accordance with the Act on Promotion of Global Warming Countermeasures. We surveyed 906 commercial buildings. The respondents were qualified energy managers (energy experts, facility managers) in the buildings of the surveyed facilities. The questionnaire was answered in paperbased or electronic form. We received responses from 167 buildings, for a response rate of $18.4 \%$.

The questionnaire inquired about the implementation status of EEMs, including $\mathrm{CO}_{2}$ emissions reduction measures; basic physical and operational information on the buildings; and investments in energy savings. The next subsection explains the question items.

\subsubsection{Survey Questions}

The survey consisted of three parts. The first part asked questions regarding the general characteristics of buildings. The second part included questions about EEMs implemented in the buildings. The third part asked EEM adoption-related questions.

\section{Buildings' Physical and Operational Characteristics}

The buildings' physical characteristics included the year of construction of the building, gross floor area, and number of gross floors by use. The building operational characteristics included the number of workers and visitors on workdays, vacancy rates, building operating time (hours per day) by use, operating frequency ("every day" or "weekday") by use, and experience of large-scale repairs/renovations for energy savings after the completion of the building construction.

\section{EEMs in a Building}

Regarding the implementation status of EEMs, we asked about the following categories: (1) lighting, (2) thermal insulation, (3) building energy management system (BEMS), (4) elevators, air conditioning (AC) and heat source, and (5) miscellaneous. In comprehensively selecting EEM items, we referred to the energy-saving measures of the ZEB Roadmap Follow-up Committee (2018). We elaborate on each category below.

First, six items were related to lighting-related EEMs: lighting fixtures with an automatic brightness adjustment function by sensor, scheduled switching (time scheduling), initial illumination correction, motion sensors, adjusting illuminance to less than $500 \mathrm{~lx}$ on the work plane in the office, and thinning out unnecessary lights. 
The first five EEMs are TMs, which require investment in expensive technology. The last EEM is an NTM, which does not require much extra cost.

Second, we selected three thermal insulation-related EEMs. First, the most basic measures of thermal insulation are blinds, eaves and sunshades. In the summer, closing blinds can keep direct sunlight out of the office and reduce unwanted solar heat gain. In the winter, closing window blinds can save energy by preserving heat even on cold days. ${ }^{8}$ Second, we inquired about the adoption of highly efficient thermal insulation materials. Finally, we asked about highly efficient thermal insulation windows.

Third, we asked about the BEMS, which is a management system that reduces energy consumption in buildings "while maintaining occupants' comfort" (Manic et al. 2016). There are three levels of BEMS implementation. First, buildings are engaged in monitoring and storing historical data on energy consumption. Second, buildings use the stored data to make a plan of energy savings. Finally, buildings use a demand control system, e.g., alerts when electricity demand is expected to be higher than the upper limit of the electricity supply.

Fourth, regarding elevator-related EEMs, we asked whether buildings had adopted a "reduction in the number of elevators operating outside regular hours" as operationally feasible in the existing facilities. We also asked if they had installed energyefficient elevators, i.e., elevators with variable voltage variable frequency (VVVF) inverters. The former measure is an NTM, and the latter is a TM.

Finally, we asked whether the buildings had installed automatic water taps or solar panels. We inquired whether they had set temperatures in an environmentally friendly manner $\left(28^{\circ} \mathrm{C}\right.$ for cooling, $20^{\circ} \mathrm{C}$ for heating) as recommended by the MOE.

\section{Other Questions Related to Energy Efficiency}

We also asked three questions related to EEM adoption. First, we asked whether the buildings had received energy audits and, if so, what types of energy audits they had received. There are various types of energy audits in Japan. First, internal audits by experts inside the firm itself are easiest to implement. Second, external experts can conduct energy audits by visiting facilities on site. For instance, energy service companies $(\mathrm{ESCOs})^{9}$ provide services for energy audits. Alternatively, suppliers and manufacturers of energy-efficient appliances conduct energy audits as part of sales. Further, power companies and gas companies conduct energy audits for their customers. Moreover, local governments and municipalities have energy audit support services, which have increased in recent decades due to growing interest in global warming. Other public organizations, such as the MOE and the Energy Conservation Center, Japan (ECCJ), offer similar services, but these energy audits have been implemented for medium- and small-sized enterprises as well as factories and buildings with annual energy consumption (crude oil equivalent) of $100 \mathrm{kl}$ or

\footnotetext{
${ }^{8}$ However, there is an energy use trade-off between light and heating and cooling.

${ }^{9} \mathrm{An}$ ESCO is a company that offers energy services, usually design, retrofitting and implementation of energy efficiency projects, after identifying energy-saving opportunities through energy audits of existing facilities. As payment, the ESCO can receive part of the return from the energy savings realized by their advice.
} 
more and less than $1500 \mathrm{kl}$ in principle. Therefore, our surveyed buildings do not focus on these public energy audits.

Second, we asked about the types of energy subsidies, if any, that the buildings had received. In Japan, regulatory agencies under national and local governments offer subsidies for investment in energy savings. For example, the ECCJ implemented several schemes for subsidy provision under both the MOE and METI.

Third, we obtained information on past investment in energy efficiency. We asked how the buildings had acquired information on energy efficiency. For example, persons in charge such as energy managers may ask vendors or search for information by themselves. Alternatively, they may receive information from energy audits or obtain information from industrial associations.

\subsection{Survey Results}

The breakdown of the prefectural distribution of the responding facilities is as follows. Of the 167 responding buildings, 65 were in Tokyo and seven were in Saitama. ${ }^{10}$ These two prefectures have implemented ETSs. The 95 facilities located in other prefectures are further divided into two groups. We refer to the first group as the five major prefectures, which include Aichi, Fukuoka, and Osaka, which have major metropolitan cities, and Chiba and Kanagawa, which are adjacent to Tokyo and the Greater Tokyo area. The rest of the facilities located in other prefectures compose the second group, the rest of the prefectures. We compare the implementation rate of each EEM in Tokyo with that in the above two groups to identify differences in technology adoption between areas with implementation and non-implementation of ETSs. Note that the samples of each question for basic building information and EEM implementation status contain only facilities from which we obtained responses.

\subsubsection{Basic Building Information}

Before explaining the results of EEM adoption, we present the basic information of the buildings for which responses were obtained. In this chapter, we gather key information on the basic building information questions. Table 2 shows summary statistics of this information.

First, we explain the physical characteristics of the buildings. The years of construction are, on average, 1993 in Tokyo and 1991 in the five major prefectures. In the rest of the prefectures, the average year of construction is 1986 . Thus, buildings in metropolitan areas, including Tokyo, tend to be newer than those elsewhere. There are also regional differences in the number of floors. Buildings in Tokyo are, on average, 6.7 stories higher than those in the five major prefectures. Moreover,

\footnotetext{
${ }^{10} \mathrm{We}$ focus only on Tokyo as an implementation prefecture in this chapter due to the small sample in Saitama.
} 
Table 2 Basic information on surveyed buildings by group

\begin{tabular}{|c|c|c|c|}
\hline & Tokyo & Five major prefectures & Rest of the prefectures \\
\hline \multicolumn{4}{|l|}{ Physical characteristics } \\
\hline \multirow[t]{2}{*}{ Year of construction } & 1993.5 & 1991.2 & 1986.4 \\
\hline & $(64)$ & $(64)$ & $(28)$ \\
\hline \multirow[t]{2}{*}{ Number of floors } & 25.8 & 19.1 & 11.6 \\
\hline & $(65)$ & $(63)$ & (29) \\
\hline \multirow[t]{2}{*}{ Total floor area $\left(\mathrm{m}^{2}\right)$} & $85,205.0$ & $59,794.0$ & $36,106.8$ \\
\hline & $(64)$ & $(64)$ & $(23)$ \\
\hline \multirow[t]{2}{*}{ Floor area by office use $\left(\mathrm{m}^{2}\right)$} & $61,660.2$ & $33,328.9$ & $14,278.4$ \\
\hline & $(48)$ & $(41)$ & $(20)$ \\
\hline \multicolumn{4}{|l|}{ Operation characteristics } \\
\hline \multirow{2}{*}{$\begin{array}{l}\text { Average number of workers and } \\
\text { visitors on workdays }\end{array}$} & 6828.9 & 2951.8 & 943.3 \\
\hline & $(60)$ & $(47)$ & $(22)$ \\
\hline \multirow[t]{2}{*}{ Vacancy rate $(\%)$} & 4.0 & 4.1 & 4.2 \\
\hline & $(58)$ & $(54)$ & $(21)$ \\
\hline \multirow{2}{*}{$\begin{array}{l}\text { Experience of large-scale } \\
\text { repairs/renovations with energy } \\
\text { savings }(\%)\end{array}$} & 25.4 & 35.0 & 7.4 \\
\hline & (58) & $(54)$ & (21) \\
\hline
\end{tabular}

Note Numbers in parentheses indicate number of samples

buildings in Tokyo are much taller than those in other regions. The average number of floors in buildings in Tokyo is more than twice that in other prefectures, excluding the five major prefectures. Consequently, the total floor area of buildings is largest in Tokyo. The share of office usage in buildings is higher in Tokyo than in other prefectures. Offices compose $72.4 \%$ of the total office floors in Tokyo, $55.7 \%$ in the five major prefectures, and $39.5 \%$ in the rest of the prefectures.

Next, we present the building operational characteristics. The number of workers and visitors in the buildings on workdays is 6828.9 in Tokyo. This number is more than twice that in the five major prefectures and more than seven times that in the rest of the prefectures. The vacancy rate does not differ greatly between the prefecture groups and is approximately $4 \%$. The share of the buildings that have carried out large-scale repairs and renovations with energy savings is largest in the five major prefectures, at $35 \%$. This proportion is $25 \%$ in Tokyo, which is approximately $10 \%$ lower than that in the five major prefectures, and $7.4 \%$ in the rest of the prefectures, which represents a large difference from that in the other prefecture groups.

\subsubsection{Implementation Status of Energy Efficiency Measures}

In the questionnaire, we asked about the implementation status of each EEM. It should be mentioned that implementation is not a binary choice. In some cases, 
buildings may install new equipment on all floors, and in other cases, they may adopt new technology on only a limited number of floors, such as in the main entrance of the building. Therefore, we asked respondents to answer regarding the degree of the implementation of each EEM by its percentage. To enable respondents to answer easily, we asked them to choose from seven categorical answers, i.e., (1) not implemented at all (0\%), (2) 0-20\%, (3) 20-39\%, (4) 40-59\%, (5) 60-79\%, (6) $80-99 \%$ and (7) fully implemented (100\%).

We show the results of EEM implementation by prefecture groups, Tokyo, the five major prefectures, and the rest of the prefectures, in Figs. 2 and 3. The number

\section{Lighting related measures}

Lighting fixtures with automatic brightness adjustment function by sensor

Scheduled switching (time scheduling)

Initial illumination correction

Motion sensor

Adjusting illuminance less than $500 \mathrm{~lx}$ on the work plane in the office

Thinning out unnecessary lights*

\section{Thermal insulation-related measures}

Highly efficient thermal insulation materials

Highly efficient thermal insulation windows

Blinds, eaves, and sunshades

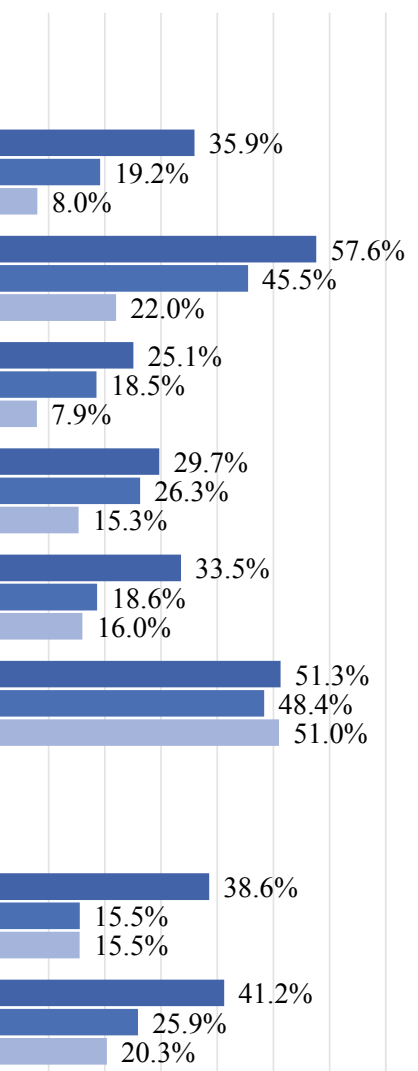

$0 \% 10 \% 20 \% 30 \% 40 \% 50 \% 60 \% 70 \% 80 \% 90 \% 100 \%$

- Tokyo $\square$ Five major prefectures $\square$ Rest of the prefectures

Fig. 2 Implementation status of lighting-related EEMs. Note Saitama prefecture is excluded from this aggregation because of the Saitama ETS effect. * indicates non-technological measures (NTM) 


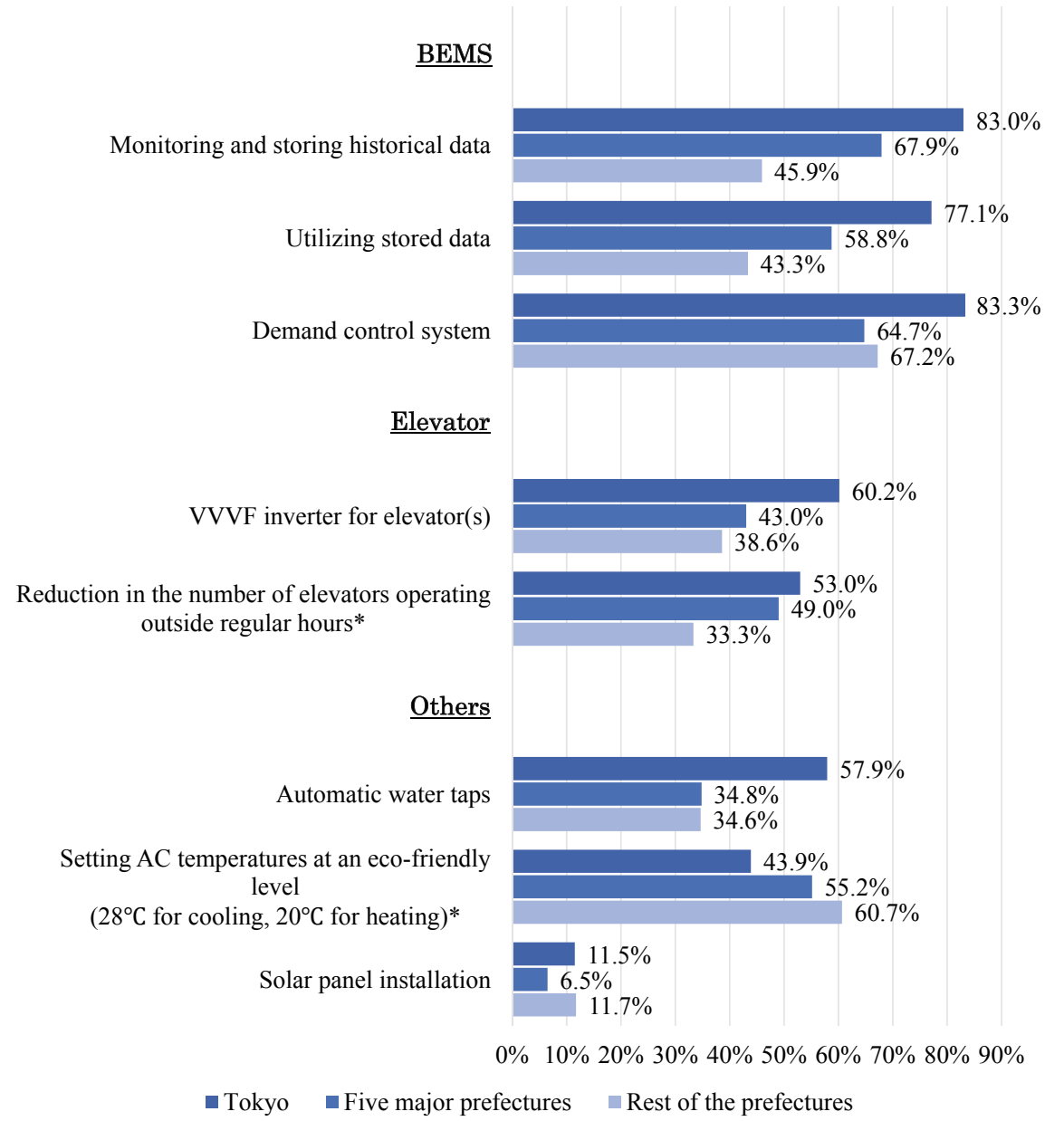

Fig. 3 Implementation status of BEMS, elevator, and other related EEMs. Note Saitama prefecture is excluded from this aggregation because of the Saitama ETS effect. * indicates non-technological measures (NTM). VVVF stands for variable voltage variable frequency

of responses for each EEM implementation status ranged from 56 to 64 buildings in Tokyo, from 54 to 62 buildings in the five major prefectures, and from 24 to 30 buildings in the rest of the prefectures.

Figure 2 illustrates the adoption of lighting-related EEMs and thermal insulationrelated EEMs. The top five lighting-related EEMs, defined as TMs, in the figure are most advanced in Tokyo, followed by the five major prefectures and the rest of the prefectures. The implementation rate of thinning out unnecessary lights, defined as an NTM, is approximately $50 \%$ in all groups.

For thermal insulation-related measures, the adoption of highly efficient materials and windows is most advanced in Tokyo among all groups. The adoption ratio of 
the conventional measures "blinds, eaves and sunshades" is high in all groups. It seems that this is basically standard equipment of building facilities even without the consideration of energy savings. For this reason, the implementation rates in all prefecture groups are quite high compared to the implementation rates of other measures.

Figure 3 shows the implementation status of BEMSs, elevators, and other related EEMs by prefecture group. For BEMS-related measures, Tokyo leads the other regions in every aspect. In particular, the implementation ratio of a "demand control system" in Tokyo is greater than that in the two other groups by at least $16 \%$. The adoption of "monitoring and storing historical data" and "utilizing stored data" is scarce in the rest of the prefectures.

Next, we examine the elevator-related EEMs. For TMs, the adoption of VVVF inverters in Tokyo is advanced compared to that in the five major prefectures and the rest of the prefectures. For NTMs, there is also a difference between Tokyo and the other two groups. The difference in a "reduction in the number of elevators operating outside regular hours" between Tokyo and the five major prefectures is approximately four percent and thus not significant. In contrast, a "reduction in the number of elevators operating outside regular hours" is not implemented as much in the rest of the prefectures. Among other EEMs, there is a clear difference between Tokyo and the two other groups in the adoption of "automatic water taps", which is also a TM. Interestingly, the practice of setting AC temperatures at an eco-friendly level is less common in Tokyo than in the two other groups. In particular, the rest of the prefectures has the highest implementation rate. In all groups, solar panel installation is low compared to the other EEMs discussed above.

To summarize these results, the ranking patterns for most of the EEMs appear similar. Regarding most EEMs, the adoption of TMs is higher in Tokyo than those in the other two groups. One plausible reason for this observation is the Tokyo ETS. Under the Tokyo ETS, the $\mathrm{CO}_{2}$ emissions from Tokyo must be reduced compared to their baseline (Chap. 6). In contrast, there is not much difference in the implementation of NTMs among the three groups. In fact, for some NTMs, the implementation rate is higher in the rest of the prefectures than in Tokyo.

\subsubsection{Energy Audits, Energy-Related Subsidies, and Information on Energy Savings}

Figure 4 shows the results regarding the implementation status of energy audits. Inhouse, subsidiary, or affiliated company technicians' energy audits compose $17.2 \%$ (26 facilities) of the total responses. More than half of those facilities (16 cases) are in Tokyo. External company energy audits have the same implementation rate as the rate of in-house, subsidiary, and affiliated company audits. Of all energy audits, 28 were performed by external companies, eight of which were performed by ESCOs. The rest of the cases were audits by private companies, such as equipment manufacturers/vendors, general contractors, and energy companies. Fifteen facilities $(10.3 \%)$ had experienced an ECCJ energy audit. As mentioned in Chap. 4, Sect. 1.2, 
In-house, subsidiary, and affiliated company
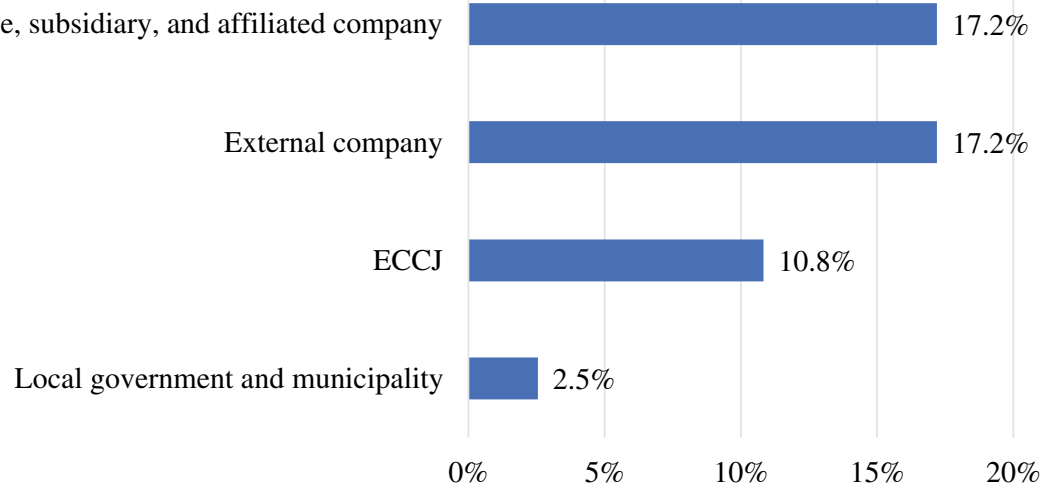

Fig. 4 Proportion of facilities with energy audits. Note Examples of external companies are ESCO, equipment manufacturer, general contractor, energy company, etc.

the ECCJ is currently implementing energy audits only for small and medium-sized enterprises and facilities with an annual energy consumption (crude oil equivalent) of $100 \mathrm{kl}$ or more and less than $1500 \mathrm{kl}$ in principle. However, before 2017, the ECCJ conducted energy audits in large-scale facilities as well. The facilities in our survey had experienced these energy audits before 2017. Finally, four energy audits were conducted by local governments and municipalities, and this number is much smaller than the number of audits conducted by other organizations.

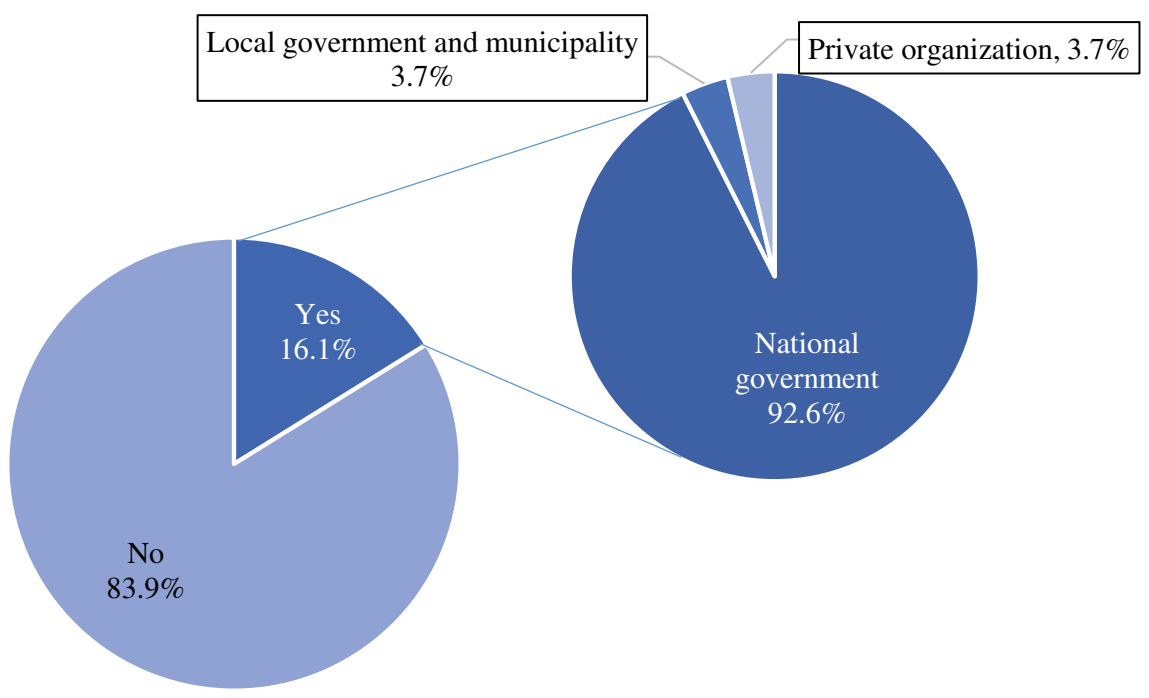

Fig. 5 Usage rate and breakdown of energy subsidies 


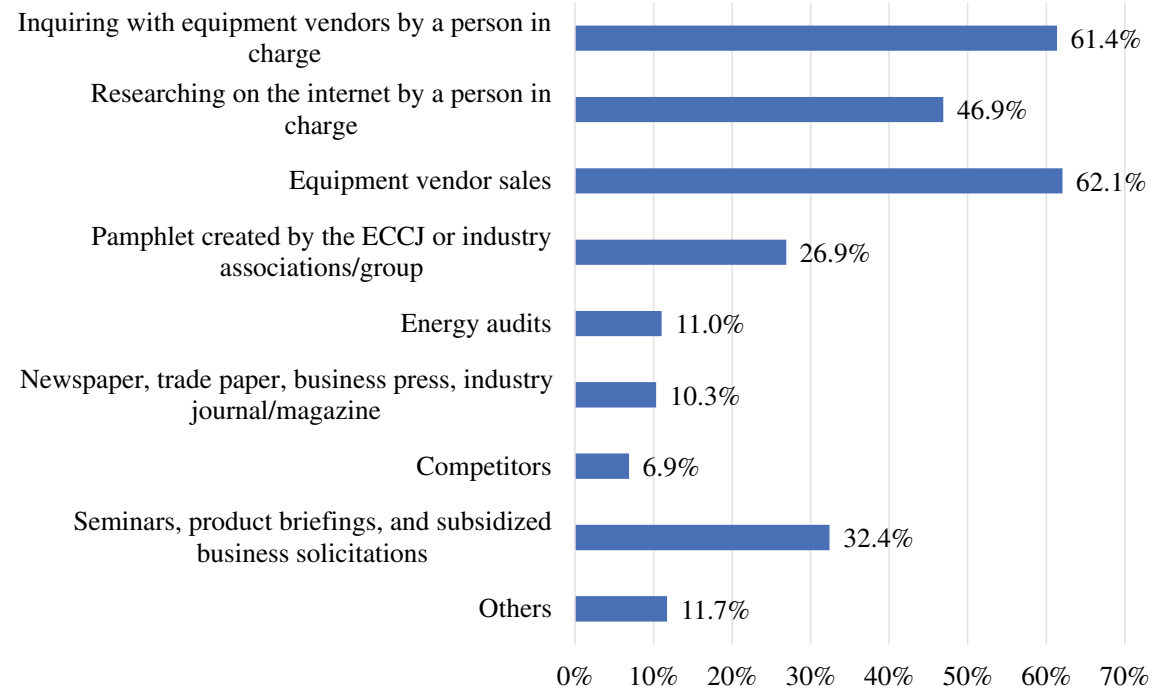

Fig. 6 Proportion of facilities how they acquired information on energy efficiency

Figure 5 illustrates whether the buildings had used subsidies when investing in energy-saving equipment. Of the 161 valid responses, 26 facilities (16.1\%) responded that they had used subsidies. Of these 26 facilities, the number of facilities using subsidies was the largest in Tokyo, at 13. In addition, we asked about the types of subsidies the buildings had used. Among 24 facilities that responded to this question, a few had used subsidies several times. Buildings that used national government subsidies accounted for 25 examples (92.6\%). There was only one case each of local government and private organization subsidies.

Figure 6 shows how information on energy conservation investments was obtained. The most common source of information was an inquiry from the person in charge of energy conservation, followed by sales from vendors/manufacturers of energy-efficient equipment. Eleven percent of facilities had obtained information from energy auditors. In other categories, there were multiple information sources, such as building design companies, the head office, and building management contractors.

\section{Conclusions}

This chapter has mainly aimed to review Japanese climate and energy conservation policies in the commercial sector and the current EEM implementation status in large-scale commercial buildings in Japan.

The first section explains the current GHG emissions in Japan and the longterm reduction goal. We observe that emission reduction in the commercial sector 
is urgently needed to achieve the Japanese NDC. Section 2 describes the mitigation policies implemented in Japan. In Sect. 3, we explain the current situations of energysaving technologies and practices in office buildings using the results of the survey we conducted in 2018.

In our survey, we found that there is potential for energy savings in office buildings. Recent research by Arimura and Abe (2020) and Chap. 7 show that ETSs have reduced GHG emissions in Japan. This chapter indicates that emission reduction was achieved by the adoption of energy-efficient technologies. Thus, CP such as an ETS or carbon tax may be useful in promoting energy-efficient technologies. However, the identification of a causal relationship between ETSs and the adoption of technologies needs more rigorous analysis.

Our survey reveals that some relatively expensive EEMs have been adopted in Tokyo but not as much in other parts of Japan. In contrast, the implementation rate of relatively inexpensive measures does not differ across regions. These observations are consistent with the interviews that we conducted with energy managers of office buildings. In general, they have started to implement relatively inexpensive measures to save energy consumption. According to Thollander et al. (2015), as of 2007, energy audits in Japan were provided for firms in non-energy-intensive industries that did not have enough expertise in energy management in-house. The authors point out that most of the recommendations from the results of energy audits are operational improvement that requires no investment but also include investment measures with short payback periods (usually less than three years). This observation was especially true in buildings outside Tokyo. Typical examples are "turning off lights when unnecessary" and "installing LED lights". As explained in Sect. 2, policy measures adopted by the government seem to have been effective in some aspects to certain degrees. However, our survey results indicate that these policy measures were not effective in promoting TMs. CP, such as the Tokyo ETS, is expected to play a crucial role in promoting TMs that have not been adopted outside Tokyo. Therefore, $\mathrm{CP}$ can be expected to contribute to the spread of relatively expensive energy-efficient technologies.

We also found that the usage of energy audits or subsidies for energy-efficient technologies is limited among office buildings. To remove barriers to the adoption of EEMs, the provision of proper information can be helpful for the promotion of energy efficiency in office buildings. According to our survey, more than half of energy audits have been implemented in Tokyo. By looking at the office buildings in Tokyo, we found that the buildings that experienced energy audits are more likely to adopt energy-efficient technologies than those without energy audit experience. This observation hints that energy audits may make managers or decision makers of office buildings aware of the benefits of energy-saving technologies under the $\mathrm{CP}$ of the Tokyo ETS. Thus, in addition to CP, policy measures promoting awareness of the merits of energy savings, such as energy audits, seem to be effective for the diffusion of these technologies.

Finally, energy-saving efforts in buildings are strongly dependent on the capacity and awareness of energy managers. Unless energy managers exert great effort to obtain proper information on energy savings, they will lack this information. The 
government should work harder so that managers of buildings can have more access to energy audits and subsidies.

Acknowledgements The survey of commercial buildings presented in this chapter was supported by the Environment Research and Technology Development Fund (JPMEERF20172007) of the Environmental Restoration and Conservation Agency.

\section{References}

Arimura TH, Abe T (2020) The impact of Tokyo emission trading scheme on office buildings: what factor contributed the emission reduction? Forthcoming in Environmental Economics and Policy Studies

Arimura TH, Iwata K (2015) The evaluation of "comprehensive management under the act on the rational use of energy" as a measure to combat climate change for the hotel industry. In: An evaluation of Japanese environmental regulations. Springer, Dordrecht

Babatunde OM, Oluseyi PO, Denwigwe IH, Akin-Adeniyi TJ (2019) Establishment of electrical energy benchmarking protocol for the assessment of the carbon emissions in hotel industry. In: Muthu SS (ed) Energy footprints of the bio-refinery, hotel, and building sectors. Springer, Singapore, pp 83-128

DeCanio SJ (1998) The efficiency paradox: bureaucratic and organizational barriers to profitable energy-saving investments. Energy Policy 26(5):441-454

Development Bank of Japan (DBJ) website. DBJ Environmentally Rated Loan Program. Accessed 17 Mar 2020. https://www.dbj-sustainability-rating.jp/en/enviro/

Gillingham K, Palmer K (2014) Bridging the energy efficiency gap: policy insights from economic theory and empirical evidence. Rev Environ Econ Policy 8(1):18-38

Hamamoto M (2020) Impact of the Saitama prefecture target-setting emissions trading program on the adoption of low-carbon technology. Environ Econ Policy Stud. https://doi.org/10.1007/s10 018-020-00270-x

Manic M, Wijayasekara D, Amarasinghe K, Rodriguez-Andina JJ (2016) Building energy management systems: the age of intelligent and adaptive buildings. IEEE Ind Electron Mag 10(1):25-39

METI website. Jigyosya kurasuwake hyokaseido ni tsuite. p 3. Accessed 18 Mar 2020. https://www. enecho.meti.go.jp/category/saving_and_new/saving/classify/pdf/h29-classify.pdf (in Japanese)

Ministry of Economy, Trade, and Industry (METI) (2018) The fifth strategic energy plan. July 2018. Accessed 12 Feb 2020. https://www.enecho.meti.go.jp/en/category/others/basic_plan/5th/pdf/str ategic_energy_plan.pdf

Ministry of the Environment (MOE) (2019) Japan's national greenhouse gas emissions in fiscal year 2018 (Preliminary Figures), 29 Nov 2019. Accessed 7 Jan 2020. https://www.env.go.jp/en/ headline/2420.html

Mitsubishi Research Institute (MRI) (2016) FY2015 report on the verification and evaluation of Assistance programs of $\mathrm{CO}_{2}$ emission reduction potential under the special account for energy measures (in Japanese)

MOE website. FY 2019 Calls for Assistance programs of $\mathrm{CO}_{2}$ emission reduction potential. Accessed 6 Apr 2020. https://www.env.go.jp/press/106710.html (in Japanese) 
Noailly J (2012) Improving the energy efficiency of buildings: the impact of environmental policy on technological innovation. Energy Econ 34:795-806

Olsthoorn M, Schleich J, Hirzel S (2017) Adoption of energy efficiency measures for non-residential buildings: technological and organizational heterogeneity in the trade. Commer Serv Sector Ecol Econ 136:240-254

Thollander P, Kimura O, Wakabayashi M, Rohdin P (2015) A review of industrial energy and climate policies in Japan and Sweden with emphasis towards SMEs. Renew Sustain Energy Rev 50:504-512

ZEB (Net Zero Energy Building) Roadmap Follow-up Committee (2018) ZEB Design Guideline: Medium-sized office edition

Dr. Hiroki Onuma is a fellow of the Research Institute of Economy, Trade and Industry (RIETI), Tokyo, Japan. He received his B.A. in Economics from Soka University in 2011, his M.A. in Environmental Studies from Tohoku University in 2013, and his Ph.D. in Engineering from Kyushu University in 2017. Prior to joining RIETI, he was a junior researcher (assistant professor) of the Research Institute for Environmental Economics and Management at Waseda University. His research focuses on environmental and energy economics and disaster management including climate change policies. He currently works to examine the impact of carbon pricing mechanisms on firms' environmental performance and residential energy consumption in Japan.

Dr. Toshi H. Arimura is a Professor of Political Science and Economics and Director of the Research Institute for Environment Economics and Management at Waseda University in Tokyo. Prior to joining Waseda, he was a Professor at Sophia University in Tokyo and was a visiting scholar with George Mason University and Resources for the Future as a recipient of the Abe Fellowship. His research interests include climate change, energy policies, air pollution regulations and voluntary environmental actions. He has published his research in academic journals such as Journal Environmental Economics and Management, Journal of Association of Environmental and Resources Economics, Environmental and Resource Economics, Ecological Economics or Energy Policy. He is a coauthor of An Evaluation of Japanese Environmental Regulation: A Quantitative Approach from Environmental Economics (Springer 2015). Dr. Arimura holds a Ph.D. in economics from the University of Minnesota, an M.Sc. in environmental sciences from the University of Tsukuba and a B.A. in history of science from the University of Tokyo. He has served on a number of Japanese government committees on environmental issues including the committees on carbon pricing (2018) and emission trading scheme (2010) of the environmental council under Ministry of the Environment. He is also a member of the Tokyo Metropolitan environmental council. He has served on advisory committees of local governments for emission trading schemes of Tokyo and Saitama. He has also been on editorial boards of academic journals such as Review of Environmental Economics and Policy, Agricultural and Resource Economics Review, Economics of Energy and Environmental Policy or Environmental Economics and Policy Studies. Since 2018, Waseda University has choses him as one of 10 next generation core researchers. He is a recipient of SEEPS Outstanding Publication Award from Society for Environmental Economics and Policy Studies (Japanese Association of Environmental Economics and Policy) and the academic award from Society of Environmental Science, Japan. 
Open Access This chapter is licensed under the terms of the Creative Commons Attribution 4.0 International License (http://creativecommons.org/licenses/by/4.0/), which permits use, sharing, adaptation, distribution and reproduction in any medium or format, as long as you give appropriate credit to the original author(s) and the source, provide a link to the Creative Commons license and indicate if changes were made.

The images or other third party material in this chapter are included in the chapter's Creative Commons license, unless indicated otherwise in a credit line to the material. If material is not included in the chapter's Creative Commons license and your intended use is not permitted by statutory regulation or exceeds the permitted use, you will need to obtain permission directly from the copyright holder.

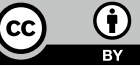

